\title{
Granular crystals in palm oil based shortening/margarine: a review
}

Viet Nguyen $^{1,2,3} *$, Tom Rimaux ${ }^{2,4}$, Vinh Truong ${ }^{3}$, Koen Dewettinck ${ }^{1,2}$ and Filip Van Bockstaele ${ }^{1,2}$

Viet Nguyen*: Viet.Nguyen@UGent,be

Tom Rimaux: tom.rimaux@vandemoortele.com

Vinh Truong: tv@hcmuaf.edu.vn

Koen Dewettinck: Koen.Dewettinck@UGent.be

Filip Van Bockstaele: Filip.VanBockstaele@UGent.be

1: Laboratory of Food Technology and Engineering, Faculty of Bioscience and Engineering, Ghent University, Belgium

2: Vandemoortele Centre 'Lipid Science and Technology', Faculty of Bioscience Engineering, Ghent University, Belgium

3: Department of Chemical Engineering, Nong Lam University-HCM City, Vietnam

4: Vandemoortele R\&D, Izegem, Belgium 


\begin{abstract}
Palm oil based shortenings and margarines are important products within the lipid industry. However, a widespread quality deterioration issue is often reported on their long term storage: the appearance of granular crystals or grains which are regarded as unwanted because of the deflecting visual appearance and the negative mouth feel during consumption. In this review, the role of fat blends composition, crystallization process and storage conditions to the formation and growth of these unwanted granular crystals will be discussed and summarized. Besides, some potential approaches in preventing the formation of granular crystals in palm oil based shortening and margarine are also introduced.
\end{abstract}

KEYWORDS: Palm oil, margarine, granular crystals, storage 


\section{INTRODUCTION}

Shortenings and margarines are important products within the lipid industry. While shortening is a simple fat blend, margarine is a water-in-oil (W/O) emulsion. In these fat based products, hard fats are used to provide a crystal network entrapping liquid oils and water droplets inside its interspaces. ${ }^{1,2}$ The selection of the appropriate hard fat is very important due to the requirement of physicochemical properties and stability during storage. Nowadays, palm oil and its fractions are considered as the most popular hard fats in the production of shortenings and margarines. Owning a good balance between saturated and unsaturated fatty acids, this low cost plant oil tends to form tiny crystals which are very stable in long term storage. ${ }^{3}$ Besides, most fat crystals of palm oil can melt easily in human body since their melting temperature is in a range of 33$40^{\circ} \mathrm{C}^{2,4}$ Moreover, palm oil has high oxidative stability since it component owns high concentration of antioxidants such as tocopherols and tocotrienols and low concentration of polyunsaturated fatty acids. In the formulation of fat based products, palm oils are often combined with other lipid materials such as soybean oil, sunflower oil, rapeseed oil and milk fat through blending to improve texture and organoleptic properties. ${ }^{5-11}$ The presence of these liquid oils and soft fats can contribute to significant change in fat polymorphism, solid fat content (SFC) and melting behaviour of the fat blends but can also cause instability issues of the fat based products, especially in long term storage at low temperature. ${ }^{12-16}$

For palm oil based shortenings and margarines, the most prevalent quality deterioration in storage is the appearance of granular crystals resulting in a graininess feeling for customers. According to many studies ${ }^{1,15,17,18}$, granular crystals can be considered as the clusters of fat crystals with the size in a range of $0.1-3 \mathrm{~mm}$ which can become visual in products stored at 5 $10^{\circ} \mathrm{C}$ after 3-6 months (Figure 1). Although early studies of granular crystals in palm blends 
have been conducted more than two decades, the understandment of the formation of these particles is quite limited and the prevention of their appearance in long term storage is still a big challenge of fat industry. In fact, there are different hypotheses on the mechanism of granular crystals formation. This review, therefore, will provide an overview picture of both internal and external factors including fat blend composition, processing and storage conditions on the formation and growth of granular crystals in stored palm oil based fat products.

\section{Figure 1 should be here}

\section{PALM OIL CRYSTALLIZATION}

Fat composition. In general, palm oil has a good balance of the ratio between saturated and unsaturated fatty acids (FAs) (Table 1). With a content of $49-68 \%$, palmitic acid (C16:0) is the major saturated FA in palm oil and its common fractions (palm olein and palm stearin), followed by stearic acid (C18:0) $( \pm 4 \%)$. For the unsaturated FA, oleic acid $(\mathrm{C} 18: 1)$ is higher in content followed by polyunsaturated FA such as linoleic acid (C18:2) ( $\pm 8 \%)$. These unsaturated FAs often distribute at sn-2 (sn: stereospecifically numbered) position in the major triacylglycerols (TAGs) of palm oil such as POO, POP, LOP, PLP and POS (Table 2). ${ }^{19}$ Most studies ${ }^{4,20-23}$ aggree that the TAG profile plays an important role in the crystallization of the palm fractions. For example, a high amount of tri-saturated TAG such as PPP or PPS is found in palm stearin while mono-saturated TAG such as LOP has higher content in palm olein. Therefore, crystallization temperature of palm stearin $\left(24-40^{\circ} \mathrm{C}\right)$ is significant higher than that of palm olein (below $0^{\circ} \mathrm{C}$ ). For palm oils, it crystallization often occurs in a range of $15-22^{\circ} \mathrm{C}$ depending on the cooling rate. ${ }^{24}$

Table 1 and 2 should be here 
Fat polymorphism and crystal morphology. In cooling, the mobility of TAGs gradually decrease resulting in the formation of crystal nucleates. Depending on the composition and the distribution (stereospecificity) of FAs in TAGs, lipid molecules are oriented into two conformations including tuning fork and stacked chair to form two layer (2L) or three layer (3L) longitudinal stacking, respectively. ${ }^{29,30}$ The first is mainly favored by TAGs containing similar FA moieties while the latter is found in mixed-FA TAGs with different chemical properties. The fat crystalline lattice (subcell) can have many different structures (polymorphism) which are often classified into three common forms including $\alpha, \beta$ ' and $\beta$ forms relating to the arrangement of TAG. In the $\alpha$ form, hexagonal subcells are formed by the perpendicular cross of straight hydrocarbon chains with methyl planes. For $\beta$ ' and $\beta$ form, zigzag hydrocarbon chains are inclined with methyl plane to create orthorhombic and triclinic subcells, respectively. ${ }^{30}$ Since the density of the chain packing is least for hexagonal structure, intermediate for orthorhombic structure and highest for triclinic structure whereas the free rotation ability of methyl planes have a counter tendency, Gibbs free energy of fat polymorphs decreases in this order: $\alpha>\beta$ ' $>\beta$. The higher Gibbs free energy means the lower $\Delta \mathrm{G}$ requirement for nuclei formation. Therefore, in rapid cooling the least stable polymorph ( $\alpha$ form) often appears first below its melting temperature and irreversible transforms to higher stability forms in further cooling. ${ }^{29,30}$

Fat polymorphism and thermal properties of common TAGs in palm oil can be found in Table 3 . The distribution of FAs in TAG molecules plays an important role in determining the polymorph of fat crystals. ${ }^{30}$ Normally, symmetric TAGs such as POP and PPP have a $\beta$ tendency while asymmetric TAGs such as PPO and POO are stable under $\beta$ ' form. ${ }^{21,31}$ Further, palm oil polymorphism also strongly depends on the cooling rate. By combining polarized light microscopy (PLM) and differential scanning calorimetry (DSC), some authors ${ }^{31-34}$ suggested that 
$\beta^{\prime}$ crystals dominated in palm oil crystallized at a rate of $3^{\circ} \mathrm{C} / \mathrm{min}$ and a coexistence of $\beta^{\prime}$ and $\beta$ crystals was discovered if lowering the cooling rate to $0.4^{\circ} \mathrm{C} / \mathrm{min}$. In a contrast, $\alpha$ crystals dominated when fast cooling palm oil and the $\alpha \rightarrow \beta^{\prime}$ polymorphic transition mainly occurred in the isothermal stages. ${ }^{35}$

\section{Table 3 should be here}

The size of fat crystals play an important role in physicochemical properties of most fat based products. For most shortening/margarine products, tiny crystals are favored due to their positive effect on stabilizing the microstructure of products as well as bringing a desirable mouthfeel. ${ }^{1,2}$ Normally, the size of crystal platelets after nucleation is smaller than $1 \mu \mathrm{m}$ and often gradually increases based on the accumulation of supercooled TAG molecules from the liquid oil to the nucleate surface. In futher cooling and storage, the agglomeration of fat crystals can occur to form needle-like crystals and spherulite-like crystals with the average size of $5 \mu \mathrm{m}$ and $20 \mu \mathrm{m}$, respectively. ${ }^{39,40}$ In general, fat crystals of palm oil are needle-like crystals under $\beta$ ' form which have appropriate size for trapping liquid oil inside the crystal networks of shortening and margarine. ${ }^{1,14,41}$ However, the polymorphic transition $\beta^{\prime} \rightarrow \beta$ of palm fat can occur in long term storage. Unlike $\beta$ ' crystals, $\beta$ crystals are often spherulite particles with the size in a range of 20 $40 \mu \mathrm{m}^{23,39}$

Figure 2 should be here

Phase behavior. Similar as most natural lipids, palm oil is a mixture of various TAGs with different polymorphic tendency. In cooling, TAG molecules can partly dissolve into each other depending on their polymorph and molecular volume to form a continuous solid solution (or

mixed crystals. ${ }^{42,43}$ For example, the inter-solubility of POP in PPP (POP: 1,3-dipalmitoyl-2- 
oleoylglycerol, PPP: tripalmitoylglycerol) is $10 \%$ and $40 \%$ under $\alpha$ and $\beta$ forms, respectively. ${ }^{45}$ In a solid solution, these TAGs often have a good compatibility and their crystals have a similar melting point. For immiscible solid components, their mixtures tend to form eutectic systems. These non-ideal systems were found in the crystallization of many binary mixture such as PPO/POP, POP/OPO and POP/POS (PPO: 1,2-dipalmitoyl-3-oleoylglycerol, OPO: 1,3-dioleoyl2-palmitoylglycerol, POS: 2-oleoyl-1,3-rac-palmitoyl-stearoylglycerol). ${ }^{38,43,45,46}$ Due to the steric hindrance between TAGs, eutectic systems often have lower melting temperatures compared with their pure components. Therefore, the presence of eutectic systems is often characterized by the presence of broad peaks on thermo-diagrams of the melting/cooling and accompanies with the SFC depression of fat blends. A specific case of an eutectic system is the formation of molecular compounds (MC) based on the combination of different TAG molecules owning similar FA moieties at certain ratios. ${ }^{29,30,43}$ In this case, two different TAG molecules often merge into a $2 \mathrm{~L}$ longitudinal stacking even though the popular form of each TAG can be $3 \mathrm{~L}$ stacking. For palm fat, MC can be formed in a binary mixture of POP/OOP (OOP: 1,2-dioleoyl3-palmitoylglycerol) and POP/PPO in a range of $10-15^{\circ} \mathrm{C}$ if the ratio of each component is equal. 46-48 The presence of these compounds is often recognized by the appearance of sub-peaks on melting and cooling profiles of TAG mixtures obtained from DSC and real-time X-ray diffraction (XRD). When the melting point between components is over $20^{\circ} \mathrm{C}$, TAG mixtures often show a monotectic behaviour or the "dillution effect" ${ }^{43}$ For example, the complete dilution was observed in crystallizing a binary mixture of TAGs with large discrepancy of melting point such as LLL/SSS or LLL/PPP (LLL: trilinolenoylglycerol, SSS: tristearoylglycerol). ${ }^{29,30}$ Due to dilution effect, SFC and the crystallization temperature of these mixtures have downward tendency to the increase of lower melting TAG concentration. ${ }^{5,49,50}$ 


\section{GRANULAR CRYSTALS IN PALM OIL BASED SHORTENING/MARGARINE}

Hypotheses of the formation of granular crystals. As demonstrated previously, granular crystals are agglomerates of fat crystals which often appear upon prolonged storage of palm oil based fat products at low temperature. ${ }^{18,51}$ As their presence is unwanted, understanding the formation of granular crystals was the objective of many studies during last two decades (Table 4). Unfortunately, the mechanism of their formation in shortening and margarine is not completely clear since it is very difficult to isolate granular crystals out of fat blends. Many studies ${ }^{2,14,17,52,53}$ considered the appearance of granular crystals as a type of "fat bloom" which was often detected in chocolate causing by the polymorphic transition $\beta^{\prime} \rightarrow \beta$ forms of high melting TAGs upon prolonged storage (Figure 3). This approach seems to be logic because fat crystals in $\beta$ form often have bigger size and tend to aggregate in comparison with those in $\beta$, form. In fact, the aggregation of $\beta$ crystals was recorded through PLM in a study of granular crystals in palm oil based shortening. ${ }^{14}$ However, in other studies of margarine produced from the blends of palm oil with butter ${ }^{18}$ and with soybean oil ${ }^{15}$, the appearance of granular crystals was visually detected before $\beta$ crystals were formed. The authors suggested that the polymorphic transition could occur after granular crystals were formed and therefore the role of $\beta$ crystals in the formation of granular crystals was not considerable. In another study of the blends between palm fat and soybean oil ${ }^{54}$, XRD analysis of granular crystals showed that these particles could be the combination of both $\beta$ crystals (core) and $\beta$ ' crystals (outer). Despite of arguments on the mechanism, all studies aggreed that the composition of the fat blends and their postcrystallization are the main drivers for the formation of granular crystals in palm oil based shortening/margarine. In fact, post-crystallization of fat crystals often strongly depends on the cooling conditions during processing and the storage conditions. 


\section{Figure 3 should be here}

\section{Table 4 should be here}

The composition of fat blends. Both shortening and margarine are fat blends based products. Spreadability, the most important property of commercial shortening/margarine has a strong relationship with the SFC of products. ${ }^{2,51,56,57}$ Therefore, some liquid oils (sunflower oil, rapeseed oil and soybean oil) are often blended with hard fat at different ratios to achieve desirable SFC. ${ }^{5,16,58-60}$ As a $\beta^{\prime}$ tending fat, palm fat is the major hard fat in margarine but it can be replaced by hydrogenated rapeseed oil or hydrogenated soybean oil in some countries. ${ }^{61-64}$ The partial replacement of palm fat by milk fat in the production of shortening/margarine to improve the organoleptic properties is also a common trend of food industry. ${ }^{12,13,65,66}$ However, the combination of different lipid materials also enhances the complexity of TAG profiles in fat blends. FA composition and TAG profile of palm oil, milk fat and some popular liquid oils in the production of shortening/margarine were summarized in Table 1 and 2, respectively. As demonstrated in Section 2.3, mixtures of TAG under solid state often have monotectic or eutectic behaviour. Monotectic behavior (or dilution effect) is often observed in crystallization of the blend between palm oil with low melting lipids which are rich in triunsaturated TAG such as rapeseed oil and sunflower oil. ${ }^{5,8,12,25}$ On the other hand, eutectic systems were found for blends between palm oil and some milk fat fractions. ${ }^{8,12,67}$ According to the authors, eutectic behaviour in these blends could relate to the difference of molecular volume between TAGs of milk fat with palm fat. The first is rich in short chain saturated FA while the later mainly includes long chain FA.

The role of both liquid oils and eutectic system on the formation of granular crystals has not yet been well studied although they can affect fat polymorphism of the blends. Many studies 
suggested that the presence of liquid TAG can accelerate the polymorphic transformation from $\beta$ ' to $\beta$ crystals which often occurs very slow in stored fat products due to the low diffusion of supercooled molecules as well as the high energy barrier of the phase transition. ${ }^{68-70}$ For example, Timms ${ }^{68}$ partly diluted crystals of milk fat - high melting fractions into milk fat- low melting fractions to induce the formation of $\beta$ crystals. Moreover, the presence of liquid oil can accelerate the agglomeration of fat crystals. ${ }^{71,72}$ In many studies, the formation of spherulite-like crystals and their clusters occurred faster when crystals of high melting TAGs in milk fat and palm fat were partly diluted into solvent such as canola or soybean oil. ${ }^{16,71}$ In fact, smaller fat crystals are only metastable in a solid solution and can become unstable if the concentration of liquid oils in fat blends increase significantly. In this case, agglomeration and Ostwald ripening often occur to form larger solid particles and reduce the Gibbs free energy in solutions. Unlike liquid oils, the presence of eutectic systems mainly relates to polymorphic tendency of MC. Some studies ${ }^{12,65}$ have found the appearance of MC in palm blends containing 30-70\% milk fats after tempering at $15^{\circ} \mathrm{C}$. The author hypothesized that these compounds could be formed based on the co-crystallization of POP in palm fat with asymmetric TAG from the middle melting fractions of milk fat. With the presence of both different TAGs in the crystal structure, MC often have a lower steric hindrance in comparison with surrounding fat crystals and therefore are $\beta-$ tending crystals. Due to the presence of MC, a high concentration of $\beta$ crystals was discovered in the blends while both palm fat and milk fat were stable in $\beta$ ' forms at same storage condition.

There are also some arguments of the role of high melting TAG such as PPP and PPS on formation of granular crystals in palm based fat products. For example, in a study of fat blends between palm fats and soybean oil ${ }^{15}$, a small addition of PPP (at a concentration of 3\%) accelerated significantly the appearance of granular crystals. Since tri-saturated TAGs tended to 
agglomerate or form $\beta$ crystals, the author suggested that the agglomeration of PPP could form the cores or crystal nucleates of granular crystals and promote further crystallization of surrounding TAGs such as POP and SOS during storage. However, another study ${ }^{16}$ showed that tri-saturated TAG at high concentration $( \pm 12 \%)$ can limit the formation of granular crystals in fat based products by lowering significant the diffusion of liquid TAG. According to this study, granular crystals appeared slower in higher SFC fat blends which had higher tri-saturated TAG concentration as well as higher amount of $\beta$ crystals.

Cooling process. The cooling process regulates fat crystallization (Figure 4). It is generally accepted that a slower cooling rate promotes the formation of larger crystals with high stability since TAG molecules have enough time to re-arrange their structures. Under fast cooling, a large number of nucleates of high melting TAGs are formed accompanying with a rapid viscosity increase and a significant decrease of particle mobility. ${ }^{73}$ The low diffusion of supercooled TAG molecules limited the further crystallization of fat crystals resulting in lower SFC and smaller crystal size. In industry, both inlet and oulet temperature of the crystallization process have considerable effects on the quality of margarine. ${ }^{74}$ Normally, the inlet temperature of W/O emulsions for the cooling process varies from $40^{\circ} \mathrm{C}$ to $60^{\circ} \mathrm{C}^{15,18,53,54,56,74} \mathrm{~A}$ lower inlet temperature can induce the crystallization of tri-saturated TAGs such as PPP and PPS before rapid crystallization occurs resulting in the formation of undesirable $\beta$ crystals in products. ${ }^{74}$ For the outlet temperature, the crystallization of palm oil below $20^{\circ} \mathrm{C}$ is often a two-stage process. In rapid cooling, $\alpha$ crystals were formed before converting to $\beta^{\prime}$ crystals and therefore a coexistance of two polymorphs was discovered in the isothermal period. ${ }^{24,35,75}$ However, the crystallization at $22^{\circ} \mathrm{C}$ only is a single step since $\beta$ ' crystals can be formed directly from the melt. This conclusion was supported by many previous studies using various methods including 
DSC, pulsed field gradient nuclear magnetic resonance (pfg-NMR), rheology analysis and $\mathrm{XRD}^{24,75}$ The authors explain that high melting TAG crystals which are $\beta$ '-tending at high temperature always appear first in cooling and orient the structure of final mixed crystals including both saturated and unsaturated TAGs. For palm oil based margarine, $\beta$ crystals are often discovered after a few weeks of storage if the outlet temperature of the product is higher than $15^{\circ} \mathrm{C} .{ }^{33}$ In this case, the lower SFC of the fat blends at higher outlet temperature of cooling process could affect the crystal networks and promote the polymorphic transition in storage.

\section{Figure 4 should be here}

Storage conditions. In many Asian countries, shortening/margarine can be preserved at ambient temperature. However, in other regions, they are often kept in low temperature before using and the fat instability can occur in this stage. The first issue is the miscibility of fat components which often strongly depends on storage temperature. As decreasing temperature, some supercooled TAGs can crystallize and the phase behaviour of fat blends can shift from monotectic behaviour to eutectic behaviour. ${ }^{43}$ For example, most studies of the blends between palm fats and milk fats revealed that eutectic behaviour and compound interaction mainly was observed in a range of $5^{\circ} \mathrm{C}$ to $10^{\circ} \mathrm{C} .{ }^{12,65,66}$ The second issue is the post-crystallization during storage due to the different crystallization kinetics of different TAGs in the fat blends. As demonstrated in previous section, the cooling process of palm based fat products is often conducted around $20^{\circ} \mathrm{C}$ to crystallize most high melting TAGs of palm fat including POP/PPO and PPP. These TAGs play a role as the major crystal networks entrapping the liquid phase in shortening and margarine. When storing at lower temperature, low melting TAGs in fat blends can slowly crystallize during post crystallization. For example, the post-crystallization of POO at

$5^{\circ} \mathrm{C}$ contributed to the agglomeration of POP resulting in the formation of granular crystals. ${ }^{16,18}$ 
Although POP is stable in $\beta$, form at $5^{\circ} \mathrm{C}$ but the polymorphic transition to $\beta$ form can be accelerated in the presence of low melting TAG such as POO since these TAGs can combine together to form MC. ${ }^{46,77,78}$ In another study ${ }^{12}$, the appearance of big $\beta$ crystals was recognized when tempering the blends of palm fat and milk fat at $15^{\circ} \mathrm{C}$. The author linked this phenomenon with the co-crystallization between POP of palm fat with some asymmetric TAG molecules in milk fat middle melting fraction which had a crystallization temperature in a range of $10-15^{\circ} \mathrm{C}$. To accelerate the formation of granular crystals in palm blends, a thermal fluctuation cycle (at $5^{\circ} \mathrm{C}$ and at $20^{\circ} \mathrm{C}$ ) is often applied to induce polymorphic transition which often occurs very slowly in solid state..$^{17,18,54,57}$ By increasing the temperature of samples above the melting point of the least stable form (for example POO), the SFC and viscosity of fat blends decreases and the concentration of liquid fat increases resulting in the agglomeration between fat crystals. Besides, the melting of a low stable form (such as $\alpha$ crystals) will provide seed crystals for the growth of higher stable form (such as $\beta$ crystals). ${ }^{29}$

Approaches to prevent the formation of granular crystals in shortening/margarine. The development of solutions to prevent granular crystals in stored palm based fat products is a big challenge of lipid industry since the formation of these particles has not yet been fully understood. Therefore, most studies focused on limiting the agglomeration between TAGs and retarding the formation of $\beta$ crystals. For palm fat, symmetric TAGs such as PPP and POP tend to precipitate into liquid oils or form MC based on the combination with other asymmetric TAGs such as PPO and POO. To modify the ratio between symmetric and asymmetric TAGs in fat blends, chemical and enzymatic interestification are useful methods since they can re-distribute FAs in TAGs. ${ }^{25,79}$ For example, an enzymatic interestification of $30 \mathrm{~h}$ could help to reduce significantly the concentration of both POP and PPP in palm fractions. ${ }^{80}$ In another study ${ }^{66}$, 
enzymatic interestification improved the miscibility between components in the blends of palm stearin with milk fat and with palm kernel oil. Similarly, this method was applied to limit the formation of $\beta$ crystals and MC in the blends between palm fat and milk fat fractions. ${ }^{65}$ Unlike hydogrenated fats and trans-fats, interestified fats are considered as safe lipids materials for food industry. There was not any relationship between the consuming of interestified fat with the increase of saturated fat in the blood lipids as well as cardiovascular disease risk..$^{37,81,82}$ However, the application of interstification method can increase significantly production cost for lipid industry including investing new equipments (for chemical interestification) and purchasing expensive catalysts (for enzymatic interestification). ${ }^{83}$

For modification of the crystallization behaviour and to control the growth of fat crystals in postcrystallization, the addition of emulsifiers at small amount (0-2\%) to the fat blend is also a popular trend in food industry. ${ }^{3,84-90}$ For this approach, the adding concentration and fatty acid moiety of these additives are key factors to their effectiveness. Some popular additives in lipid industry are monoaclyglycerols (MAG) and diacylglycerols (DAG) which are the byproducts in manufacturing and purifying palm oils. Many studies revelead that the presence of DAG could stabilize $\beta^{\prime}$ crystals and limit the polymorphic transition from $\beta^{\prime}$ to $\beta$ crystals in palm based shortening/margarine. ${ }^{91,92}$ In another study ${ }^{53}$, MAG was applied to alleviate the crystallization rate of palm stearin and limit the graininess feeling of palm based margarine. Some hydrophobic additives such as sorbital ester and sucrose esters could be applied for modifying the crystallization behaviour of both dairy fat ${ }^{84,89,93}$ and palm fat ${ }^{51,87,90,94,95}$. For palm based shortening, sucrose esters of stearic acid can be added to decrease the size of fat crystals resulting in preventing the formation of large granular crystals ${ }^{51}$ In another study, the posthardening and the formation of granular crystals in palm oil based shortening could be controlled 
by adding talc, a popular clay mineral in many food and cosmetic products. ${ }^{78}$ However, the addition of emulsifiers also had miscellaneous effects on physicochemical properties of fat based products depending on the interactions between additives and raw materials. ${ }^{96,97}$ For example, sorbital tristearate (Span 65) can increase significantly the hardness of palm oil based margarine as well as the stability of $\beta^{\prime}$ polymorph in storage ${ }^{90}$ but it can not prevent the formation of POP granular crystals ${ }^{51}$. In another studies, the authors suggested that margarine using emulsifiers based on MAG/DAG often have soft texture and weaker network structure. ${ }^{56,57,91}$ Moreover, the consumer's perception is also a potential barrier for the application of additives in food products. ${ }^{98,99}$

\section{RESEARCH GAP AND FUTURE PROSPECT}

In the production of industrial shortening/margarine, crystallization of fat blends often undergoes strong shear flow during cooling (using scraped surface heat exchangers). However, many studies concerning the formation of granular crystals in fat based products used samples crystallized under static conditions without a shear step (in freezer). ${ }^{12,17,52}$ In some other cases, samples were prepared under shear crystallization but the role of shear on the formation of granular crystals was ignored. ${ }^{15,18,53}$ In fact, both crystal size and fat polymorphism could be significant influenced by shear flow. ${ }^{2,97,100,101}$ Crystal growth can be considered as a dynamic balance between two phenomena: the accumulation of TAGs on nucleate surface and the dilution of molecules from fat crystals into solution. ${ }^{102}$ When shear was applied in crystallization, nano platelets are often oriented by flow resulting in limiting their further aggregation. ${ }^{103,104}$ Therefore, crystal thickness and the crystalline orientation strongly depend on applied shear rate. ${ }^{102}$ For fat polymorphs, the effect of shear on the formation of $\beta$ crystals in palm based fat products is quite complicated. Some studies showed that high shear flow retarded the $\beta^{\prime} \rightarrow \beta$ 
polymorphic transition in shortening ${ }^{58}$ but accelerated this transformation in margarine $e^{57}$. Therefore, the role of shear rate should be accounted more in depth in further studies of granular crystals in palm oil based shortening and margarine.

\section{CONCLUDING REMARKS}

From the findings summarized in this review, the formation of granular crystals, the most instability issue in palm blends based shortening/margarine is the combining result of both internal and external factors. While post-crystallization of fat blends in the storage strongly depends on the fat compatibility between TAGs and storage condition, the thermal and mechanical processing play an important role in controlling the polymorphism and size of fat crystals. In fact, there is a large discrepancy of the microstructure between samples prepared in laboratory and industrial scale, which limits the effectiveness of solutions in preventing grain development in commercial fat products. The studies of granular crystals in palm blend based shortening/margarine, therefore, need to consider carefully all aspects of the procedure to build appropriate solutions. Due to the difficulties in changing the fat components of products, the addition of crystals modifiers as well as the modification of parameters of food processing can be promised approaches to eliminate or alleviate the formation of undesirable fat crystals in industrial products.

\section{REFERENCES}

(1) Miskandar, M. S.; Man, Y. C.; Yusoff, M. S. A.; Rahman, R. A. Quality of margarine: fats selection and processing parameters. Asia Pac. J. Clin. Nutr. 2005, 14, 387-395.

(2) Aini, I. N.; Miskandar, M. S. Utilization of palm oil and palm products in shortenings and margarines. Eur. J. Lipid Sci. Technol. 2007, 109, 422-432.

(3) Ribeiro, A. P. B.; Masuchi, M. H.; Miyasaki, E. K.; Domingues, M. A. F.; Stroppa, V. L. Z.; de Oliveira, G. M.; Kieckbusch, T. G. Crystallization modifiers in lipid systems. $J$. Food Sci. Technol. 2015, 52, 3925-3946. 
(4) Che Man, Y. ; Haryati, T.; H.M, G.; Asbi, B. Composition and thermal profile of crude palm oil and its products. J. Am. Oil Chem. Soc. 1999, 76, 237-242.

(5) Barbosa, K. M.; Cardoso, L. P.; Ribeiro, A. P. B.; Kieckbusch, T. G.; Buscato, M. H. M. Crystallization of low saturated lipid blends of palm and canola oils with sorbitan monostearate and fully hydrogenated palm oil. J. Food Sci. Technol. 2018, 55, 11041115.

(6) Danthine, S.; Delatte, S.; Blecker, C.; Smith, K. W.; Bhaggan, K. Crystallization behaviour of binary fat blends containing shea stearin as hard fat. Eur. J. Lipid Sci. Technol. 2015, 117, 1687-1699.

(7) Campbell, S. D.; Goff, H. D.; Rousseau, D. Modeling the nucleation and crystallization kinetics of a palm stearin/canola oil blend and lard in bulk and emulsified form. J. Am. Oil Chem. Soc. 2004, 81, 213-219.

(8) Lida, H. M. D. N.; Md. Ali, A. R. Physicochemical characteristics of palm-based oil blends for the production of reduced fat spreads. J. Am. Oil Chem. Soc. 1998, 75, 16251631.

(9) Kloek, W.; Walstra, P.; Van Vliet, T. Crystallization kinetics of fully hydrogenated palm oil in sunflower oil mixtures. J. Am. Oil Chem. Soc. 2000, 77, 389-398.

(10) Kaufmann, N.; Kirkensgaard, J. J. K.; Andersen, U.; Wiking, L. Shear and rapeseed oil addition affect the crystal polymorphic behavior of milk fat. J. Am. Oil Chem. Soc. 2013, 90, 871-880.

(11) Abd El-Aziz, M.; Mahran, G. A.; Asker, A. A.; Sayed, A. F.; El-Hadad, S. S. Blending of butter oil with refined palm oil: Impact on physicochemical properties and oxidative stability. Int. J. Dairy Sci. 2013, 8, 36-47.

(12) Danthine, S. Physicochemical and structural properties of compound dairy fat blends. Food Res. Int. 2012, 48, 187-195.

(13) Nor Hayati, I.; Aminah, A.; Mamot, S.; Nor Aini, I.; Noor Lida, H. M. Physical characteristics of modified milk fat in high-melting fat preparation. Int. J. Food Sci. Nutr. 2002, 53, 43-54.

(14) Meng, Z.; Geng, W.; Wang, X.; Liu, Y. Fat crystal migration and aggregation and polymorphism evolution during the formation of granular crystals in beef tallow and palm oil. J. Agric. Food Chem. 2013, 61, 12676-12682.

(15) Tanaka, L.; Miura, S.; Yoshioka, T. Formation of granular crystals in margarine with excess amount of palm oil. J. Am. Oil Chem. Soc. 2007, 84, 421-426.

(16) Shimomura, Y.; Tsuchiya, M.; Ueno, S.; Shiota, M. Effect of triacylglycerol compositions and physical properties on the granular crystal formation of fat blends. J. Am. Oil Chem. Soc. 2019, 96, 35-42.

(17) Watanabe, A.; Tashima, I.; Matsuzaki, N.; Kurashige, J.; Sato, K. On the formation of 
granular crystals in fat blends containing palm oil. J. Am. Oil Chem. Soc. 1992, 69, 10771080.

(18) Miura, S.; Konishi, H. Crystallization behavior of 1,3-dipalmitoyl-2-oleoyl-glycerol and 1-palmitoyl-2,3-dioleoyl-glycerol. Eur. J. Lipid Sci. Technol. 2001, 103, 804-809.

(19) Sambanthamurthi, R.; Sundram, K.; Tan, Y. A. Chemistry and biochemistry of palm oil; Prog. Lipid Res. 2000, 39, 507-558.

(20) Ikeda, E.; Ueno, S.; Miyamoto, R.; Sato, K. Phase behavior of a binary mixture of 1,3dipalmitoyl-2-oleoyl-sn-glycerol and 1,3-dioleoyl-2-palmitoyl-sn-glycerol in n-dodecane solution. J. Phys. Chem. B 2010, 114, 10961-10969.

(21) Braipson-Danthine, S.; Gibon, V. Comparative analysis of triacylglycerol composition, melting properties and polymorphic behavior of palm oil and fractions. Eur. J. Lipid Sci. Technol. 2007, 109, 359-372.

(22) Tan, C. P.; Man, Y. B. C.; Che Man, Y. B. Differential scanning calorimetric analysis of edible oils: comparison of thermal properties and chemical composition. J. Am. Oil Chem. Soc. 2000, $77,143-155$.

(23) Podchong, P.; Tan, C. P.; Sonwai, S.; Rousseau, D. Composition and crystallization behavior of solvent-fractionated palm stearin. Int. J. Food Prop. 2018, 21, 496-509.

(24) De Graef, V.; Dewettinck, K.; Verbeken, D.; Foubert, I. Rheological behavior of crystallizing palm oil. Eur. J. Lipid Sci. Technol. 2006, 108, 864-870.

(25) Lida, H. M. D.; Sundram, K.; Siew, W. L.; Aminah, A.; Mamot, S. TAG composition and solid fat content of palm oil, sunflower oil, and palm kernel olein blends before and after chemical interesterification. J. Am. Oil Chem. Soc. 2002, 79, 1137-1144.

(26) Neff, W. E.; Byrdwell, W. Soybean oil triacylglycerol analysis by reversed-phase highperformance liquid chromatography coupled with atmospheric pressure chemical ionization mass spectrometry. J. Am. Oil Chem. Soc. 1995, 72, 1185-1191.

(27) Endo, Y.; Ohta, A.; Kido, H.; Kuriyama, M.; Sakaguchi, Y.; Takebayashi, S.; Hirai, H.; Murakami, C.; Wada, S. Determination of triacylglycerol composition in vegetable oils using high-performance liquid chromatography: A collaborative study. J. Oleo Sci. 2011, $60,451-456$.

(28) Lopez, C.; Bourgaux, C.; Lesieur, P.; Riaublanc, A.; Ollivon, M. Milk fat and primary fractions obtained by dry fractionation. 1. Chemical composition and crystallisation properties. Chem. Phys. Lipids 2006, 144, 17-33.

(29) Himawan, C.; Starov, V. M.; Stapley, A. G. F. Thermodynamic and kinetic aspects of fat crystallization. Adv. Colloid Interface Sci. 2006, 122, 3-33.

(30) Sato, K. Crystallization behaviour of fats and lipids - a review. Chem. Eng. Sci. 2001, 56, 2255-2265. 
(31) Chong, C. L.; Kamarudin, Z.; Lesieur, P.; Marangoni, A.; Bourgaux, C.; Ollivon, M. Thermal and structural behaviour of crude palm oil: crystallisation at very slow cooling rate. Eur. J. Lipid Sci. Technol. 2007, 109, 410-421.

(32) Vuillequez, A.; Koza, L.; Youssef, B.; Bridier, M.; Saiter, J. M. Thermal and structural behavior of palm oil. Influence of cooling rate on fat crystallization. Macromol. Symp. 2010, 290, 137-145.

(33) Miskandar, M. S.; Che Man, Y. B.; Yusoff, M. S. A.; Abdul Rahman, R. Effect of scraped-surface tube cooler temperatures on the physical properties of palm oil margarine. J. Am. Oil Chem. Soc. 2002, 79, 931-936.

(34) Litwinenko, J. W.; Rojas, A. M.; Gerschenson, L. N.; Marangoni, A. G. Relationship between crystallization behavior, microstructure, and mechanical properties in a palm oilbased shortening. J. Am. Oil Chem. Soc. 2002, 79, 647-654.

(35) Foubert, I.; Fredrick, E.; Vereecken, J.; Sichien, M.; Dewettinck, K. Stop-and-return DSC method to study fat crystallization. Thermochim. Acta 2008, 471, 7-13.

(36) Adlof, R. O.; List, G. R. Synthesis and Physical Properties of Symmetrical and NonSymmetrical Triacylglycerols Containing Two Palmitic Fatty Acids. J. Am. Oil Chem. Soc. 2008, 85, 99-104.

(37) Berry, S. E. Triacylglycerol structure and interesterification of palmitic and stearic acidrich fats: An overview and implications for cardiovascular disease. Nutr. Res. Rev. 2009, $22,3-17$.

(38) Zhang, L.; Ueno, S.; Miura, S.; Sato, K. Binary phase behavior of 1,3-dipalmitoyl-2oleoyl-sn-glycerol and 1,2-dioleoyl-3-palmitoyl-rac-glycerol. J. Am. Oil Chem. Soc. 2007, 84, 219-227.

(39) Chawla, P.; Smith, A. K. Crystal morphology of shortenings and margarines. Food struct. 1990, 9, 329-336.

(40) Chauhan, R. R.; Dullens, R. P. A.; Velikov, P. K.; Aarts, D. G. A. L. The effect of colloidal aggregates on fat crystal networks. Food Funct. 2017, 8, 352-359.

(41) Miskandar, M. S.; Che Man, Y. B.; Rahman, R. A.; Aini, I. N.; Yusoff, M. S. A. Palm oil crystallization: Effects of cooling time and oil content. J. Food Lipids 2004, 11, 190-207.

(42) Sato, K.; Ueno, S. Polymorphism in fats and oils. In Bailey's Industrial Oil and Fat Products; Shahidi, F.; Ed. Wiley-VCH, 2005; pp 77-120.

(43) Timms, R. E. Phase behaviour of fats and their mixtures. Prog. Lipid Res. 1984, 23, 1-38.

(44) Acevedo, N. C.; Marangoni, A. G. Toward Nanoscale Engineering of Triacylglycerol Crystal Networks. Cryst. Growth Des. 2010, 10, 3334-3339.

(45) Minato, A.; Ueno, S.; Yano, J.; Wangb, Z. H.; Seto, H.; Amemiya, Y.; Sato, K. Synchrotron radiation X-ray diffraction study on phase behavior of PPP-POP binary 
mixtures. J. Am Oil Chem. Soc. 1996, 73, 1567-1572.

(46) Minato, A.; Ueno, S.; Yano, J.; Smith, K.; Seto, H.; Amemiya, Y.; Sato, K. Thermal and structural properties of sn-1,3-dipalmitoyl-2-oleoylglycerol and sn-1,3-dioleoyl-2palmitoylglycerol binary mixtures examined with synchrotron radiation X-ray diffraction. J. Am Oil Chem. Soc. 1997, 74, 1213-1220.

(47) Minato, A.; Ueno, S.; Smith, K; Amemiya, Y.; Sato, K. Thermodynamic and kinetic study on phase behavior of binary mixtures of POP and PPO forming molecular compound systems. J. Phys. Chem. B 1997, 101, 3498-3505.

(48) Bayés-Garcia, L.; Calvet, T.; Cuevas-Diarte, M. A.; Ueno, S.; Sato, K. Phase behavior of binary mixture systems of saturated-unsaturated mixed-acid triacylglycerols: Effects of glycerol structures and chain-chain interactions. J. Phys. Chem. B 2015, 119, 4417-4427.

(49) Mihara, H.; Ishiguro, T.; Fukano, H.; Taniuchi, S.; Ogino, K. Effect of crystallization temperature of palm oil on its crystallization. IV. The influence of tripalmitoylglycerol (PPP) on the crystallization of 1,3-dipalmitoyl-2-oleoyl-glycerol (POP) and 1,2-dioleoyl3-palmitoyl-glycerol (POO). J. Oleo Sci. 2007, 56, 223-230.

(50) Takeuchi, M.; Ueno, S.; Sato, K. Synchrotron radiation SAXS / WAXS study of polymorph-dependent phase behavior of binary mixtures of saturated monoacid triacylglycerols. Cryst. Growth Des. 2003, 3, 369-374.

(51) Garbolino, C.; Bartoccini, M.; Flöter, E. The influence of emulsifiers on the crystallisation behaviour of a palm oil-based blend. Eur. J. Lipid Sci. Technol. 2005, 107, 616-626.

(52) Meng, Z.; Liu, Y. F.; Jin, Q. Z.; Huang, J. H.; Song, Z. H.; Wang, F. Y.; Wang, X. G. Characterization of graininess formed in all beef tallow-based shortening. J. Agric. Food Chem. 2010, 58, 11463-11470.

(53) Saadi, S.; Ariffin, A. A.; Ghazali, H. M.; Miskandar, M. S.; Abdulkarim, S. M.; Boo, H. C. Effect of blending and emulsification on thermal behavior, solid fat content, and microstructure properties of palm oil-based margarine fats. J. Food Sci. 2011, 76, 21-30.

(54) Tanaka, L.; Tanaka, K.; Yamato, S.; Ueno, S.; Sato, K. Microbeam X-ray diffraction study of granular crystals formed in water-in-oil emulsion. Food Biophys. 2009, 4, 331339.

(55) Meng, Z.; Liu, Y. F.; Jin, Q. Z.; Huang, J. H.; Song, Z. H.; Wang, F. Y.; Wang, X. G. Comparative analysis of lipid composition and thermal, polymorphic, and crystallization behaviors of granular crystals formed in beef tallow and palm oil. J. Agric. Food Chem. 2011, 59, 1432-1441.

(56) Saadi, S.; Ariffin, A. A.; Ghazali, H. M.; Abdulkarim, M. S.; Boo, H. C.; Miskandar, M. S. Crystallisation regime of w/o emulsion [e.g. multipurpose margarine] models during storage. Food Chem. 2012, 133, 1485-1493.

(57) Shiota, M.; Iwasawa, A.; Kotera, M.; Konno, M.; Isogai, T.; Tanaka, L. Effect of fatty acid composition of monoglycerides and shear on the polymorph behavior in water-in- 
palm oil-based blend. J. Am Oil Chem. Soc. 2011, 88, 1103-1111.

(58) Konno, M.; Wasawa, Iwasawa, A.; Isogai, T.; Tanaka, L.; Murakami, M.; Shiota, M. Effect of shearing on crystallization of palm oil-based fat blends. Food Sci. Technol. Res. 2012, 18, 375-382.

(59) Choi, H.; Lee, E.; Lee, K. G. Quality evaluation of noble mixed oil blended with palm and canola oil. J. Oleo Sci. 2014, 63, 653-660.

(60) Roiaini, M.; Norhayati, H. Physicochemical properties of canola oil, olive oil and palm olein blends. Int. Food Res. J. 2015, 22, 1227-1233.

(61) Müller, H.; Jordal, O.; Kierulf, P.; Kirkhus, B.; Pedersen, J. I. Replacement of partially hydrogenated soybean oil by palm oil in margarine without unfavorable effects on serum lipoproteins. Lipids 1998, 33, 879-887.

(62) List, G. R.; Byrdwell, W. C.; Steidley, K. R.; Adlof, R. O.; Neff, W. E. Triacylglycerol structure and composition of hydrogenated soybean oil margarine and shortening basestocks. J. Agric. Food Chem. 2005, 53, 4692-4695.

(63) Simões, I. S.; Gioielli, L. A. Crystal morphology of binary and ternary mixtures of hydrogenated fats and soybean oil. Brazilian Arch. Biol. Technol. 1999, 43, 241-248.

(64) Garsetti, M.; Balentine, D. A.; Zock, P. L.; Blom, W. A. M.; Wanders, A. J. Fat composition of vegetable oil spreads and margarines in the USA in 2013: A national marketplace analysis. Int. J. Food Sci. Nutr. 2016, 67, 372-382.

(65) Danthine, S.; Lefébure, E.; Trinh, H. N.; Blecker, C. Effect of palm oil enzymatic interesterification on physicochemical and structural properties of mixed fat blends. J. Am Oil Chem. Soc. 2014, 91, 1477-1487.

(66) Nor Hayati, I.; Aminah, A.; Mamot, S.; Nor Aini, I.; Noor Lida, H. M.; Sabariah, S. Melting characteristic and solid fat content of milk fat and palm stearin blends before and after enzymatic interesterification. J. Food Lipids 2000, 7, 175-193.

(67) Vereecken, J.; Foubert, I.; Smith, K. W.; Sassano, G. J.; Dewettinck, K. Crystallization of model fat blends containing symmetric and asymmetric monounsaturated triacylglycerols. Eur. J. Lipid Sci. Technol. 2010, 112, 233-245.

(68) Timms, R. E. The phase behaviour and polymorphism of milk fat, milk fat fractions and fully hardened milk fat. Australian Journal of Dairy Technology 1980, 35, 47-53.

(69) Sato, K. Molecular aspects in fat polymorphism. In Crystallization and Solidification Properties of Lipids; Widlak, N.; Hartel, R.; Narine, S., Eds.; AOCS Press, 2001; pp 1-16.

(70) Rousseau, D.; Hodge, S. M.; Nickerson, M. T.; Paulson, A. T. Regulating the $\beta^{\prime} \rightarrow \beta$ polymorphic transition in food fats. J. Am Oil Chem. Soc. 2005, 82, 7-12.

(71) Rousseau, D.; Hill, A. R.; Marangoni, A. G. Restructuring butterfat through blending and chemical interesterification. J. Am Oil Chem. Soc. 1996, 73, 973-981. 
(72) Maleky, F.; Acevedo, N. C.; Marangoni, A. G. Cooling rate and dilution affect the nanostructure and microstructure differently in model fats. Eur. J. Lipid Sci. Technol. 2012, 114, 748-759.

(73) Zhang, X.; Li, L.; Xie, H.; Liang, Z.; Su, J.; Liu, G.; Li, B. Comparative analysis of thermal behavior, isothermal crystallization kinetics and polymorphism of palm oil fractions. Molecules 2013, 18, 1036-1052.

(74) Miskandar, M. S.; Che Man, Y. B.; Yusoff, M. S. A.; Abdul Rahman, R. Effect of emulsion temperature on physical properties of palm oil-based margarine. J. Am Oil Chem. Soc. 2002, 79, 1163-1168.

(75) Chen, C. E.; Lai, O. M.; Ghazali, H. M.; Chong, C. L. Isothermal crystallization kinetics of refined palm oil. J. Am Oil Chem. Soc. 2002, 79, 403-410.

(76) Campos, R.; Narine, S. S.; Marangoni, A. G. Effect of cooling rate on the structure and mechanical properties of milk fat and lard. Food Res. Int. 2002, 35, 971-981.

(77) Minato, A.; Yano, J.; Ueno, S.; Smith, K.; Sato, K. FT-IR study on microscopic structures and conformations of POP-PPO and POP-OPO molecular compounds. Chem. Phys. Lipids 1997, 88, 63-71.

(78) Yoshikawa, S.; Kida, H.; Matsumura, Y.; Sato, K. Adding talc particles improves physical properties of palm oil-based shortening. Eur. J. Lipid Sci. Technol. 2016, 118, 1007-1017.

(79) Noor Lida, H. M. D.; Kalyana, S.; Nor Aini, I. Effect of chemical interesterification on triacylglycerol and solid fat contents of palm stearin, sunflower oil and palm kernel olein blends. Eur. J. Lipid Sci. Technol. 2007, 109, 147-156.

(80) Clercq, N. De; Danthine, S.; Mai, T. N., V. Gibon; K. Dewettinck. Enzymatic interesterification of palm oil and fractions : monitoring the degree of interesterification using different methods. J. Am Oil Chem. Soc. 2012, 89, 219-229.

(81) Meijer, G. W.; Weststrate, J. A. Interesterification of fats in margarine: Effect on blood lipids, blood enzymes, and hemostasis parameters. Eur. J. Clin. Nutr. 1997, 51, 527-534.

(82) Mensink, R. P.; Sanders, T. A.; Baer, D. J.; Hayes, K. C.; Howles, P. N.; Marangoni, A. The increasing use of interesterified lipids in the food supply and their effects on health parameters. Adv Nutr. 2016, 7, 719-729.

(83) Berry, S. E.; Bruce, J. H.; Steenson, S.; Stanner, S.; Buttriss, J. L.; Spiro, A.; Gibson, P. S. Interesterified fats: What are they and why are they used? A briefing report from the roundtable on interesterified fats in foods. Nutr. Bull. DOI: 10.111/nbu.12397. Published online: October 23, 2019.

(84) Cerdeira, M.; Pastore, V.; Vera, L. V.; Martini, S.; Candal, R. J.; Herrera, M. L. Nucleation behavior of blended high-melting fractions of milk fat as affected by emulsifiers. Eur. J. Lipid Sci. Technol. 2005, 107, 877-885.

(85) Verstringe, S.; Danthine, S.; Blecker, C.; Dewettinck, K. Influence of a commercial 
monoacylglycerol on the crystallization mechanism of palm oil as compared to its pure constituents. Food Res. Int. 2014, 62, 694-700.

(86) Basso, R. C.; Ribeiro, A. P. B.; Masuchi, M. H.; Gioielli, L. A.; Gonçalves, L. A. G.; Santos, A. O.; Cardoso, L. P.; Grimaldi, R. Tripalmitin and monoacylglycerols as modifiers in the crystallisation of palm oil. Food Chem. 2010, 122, 1185-1192.

(87) Domingues, M. A. F.; Da Silva, T. L. T.; Ribeiro, A. P. B.; Chiu, M. C.; Gonçalves, L. A. G. Sucrose behenate as a crystallization enhancer for soft fats. Food Chem. 2016, 192, 972-978.

(88) Rizzo, G.; Norton, J. E.; Norton, I. T. Emulsifier effects on fat crystallisation. Food Struct. 2014, 4, 27-33.

(89) Huck-Iriart, C.; Candal, R. J.; Herrera, M. L. Effects of addition of a palmitic sucrose ester on low-trans-fat blends crystallization in bulk and in oil-in-water emulsions. Food Biophys. 2009, 4, 158-166.

(90) Domingues, M. A. F.; Da Silva, T. L. T.; Ribeiro, A. P. B.; Chiu, M. C.; Gonçalves, L. A. G. Structural characteristics of crystals formed in palm oil using sorbitan tristearate and sucrose stearate. Int. J. Food Prop. 2018, 21, 618-632.

(91) Cheong, L. Z.; Tan, C. P.; Long, K.; Yusoff, M. S. A.; Laia, O. M. Physicochemical, textural and viscoelastic properties of palm diacylglycerol bakery margarine during storage. J. Sci. Food Agric. 2010, 90, 2310-2317.

(92) Saberi, A. H.; Tan, C. P.; Lai, O. M. Phase behavior of palm oil in blends with palm-based diacylglycerol. J. Am. Oil Chem. Soc. 2011, 88, 1857-1865.

(93) Martini, S.; Puppo, M. C.; Hartel, R. W.; Herrera, M. L. Effect of sucrose esters and sunflower oil addition on crystalline microstructure of a high-melting milk fat fraction. $J$. Food Sci. 2002, 67, 3412-3418.

(94) Chen, C.; Zhang, H.; Bi, Y.; Cheong, L. Effects of sucrose esters on isothermal crystallization of palm oil-based blend. J. Am. Oil Chem. Soc. 2015, 92, 277-286.

(95) Awad, T.; Sato, K. Effects of hydrophobic emulsifier additives on crystallization behavior of palm mid fraction in oil-in-water emulsion. J. Am. Oil Chem. Soc. 2001, 78, 837-842..

(96) Smith, K. W.; Bhaggan, K.; Talbot, G.; Van Malssen, K. F. Crystallization of fats: Influence of minor components and additives. J. Am. Oil Chem. Soc. 2011, 88, 10851101.

(97) Patel, A. R.; Dewettinck, K. Current update on the influence of minor lipid components, shear and presence of interfaces on fat crystallization. Curr. Opin. Food Sci. 2015, 3, 6570 .

(98) Shim, S. M.; Seo, S. H.; Lee, Y.; Moon, G. I.; Kim, M. S.; Park, J. H. Consumers' knowledge and safety perceptions of food additives: Evaluation on the effectiveness of transmitting information on preservatives. Food Control 2011, 22, 1054-1060. 
(99) Bearth, A.; Cousin, M. E.; Siegrist, M. The consumer's perception of artificial food additives: Influences on acceptance, risk and benefit perceptions. Food Qual. Prefer. 2014, 38, 14-23.

(100) Sato, K.; Bayes-Garcia, L.; Calvet, T.; Cuevas-Diarte, M. A.; Ueno, S. External factors affecting polymorphic crystallization of lipids. Eur. J. Lipid Sci. Technol. 2013, 115, $1224-1238$

(101) Narine, S. S.; Humphrey, K. L. A comparison of lipid shortening functionality as a function of molecular ensemble and shear: Microstructure, polymorphism, solid fat content and texture. Food Res. Int. 2004, 37, 28-38.

(102) Mazzanti, G.; Marangoni, A. G.; Idziak, S. H. J. Synchrotron study on crystallization kinetics of milk fat under shear flow. Food Res. Int. 2009, 42, 682-694.

(103) Mazzanti, G.; Guthrie, S. E.; Sirota, E. B.; Marangoni, A. G.; Idziak, S. H. J. Orientation and phase transitions of fat crystals under shear. Cryst. Growth Des. 2003, 3, 721-725.

(104) Mudge, E. M.; Mazzanti, G. Rheo-NMR measurements of cocoa butter crystallized under shear flow. Cryst. Growth Des. 2009, 9, 3111-3118.

\section{ACKNOWLEDGMENTS}

We gratefully acknowledge the financial support of the Ministry of Education and Training, Vietnam (The Scholarship Program 911) for the research. 
Table 1. Fatty acid composition of palm fractions in comparison with some common fats and oils ${ }^{12,22,25-27}$

\begin{tabular}{rrrrrrrr}
\hline $\begin{array}{r}\text { Fatty } \\
\text { acid }\end{array}$ & Palm oil & $\begin{array}{r}\text { Palm } \\
\text { olein }\end{array}$ & $\begin{array}{r}\text { Palm } \\
\text { stearin }\end{array}$ & Milk fat & Soybean & Sunflower & Canola \\
(FA) & & & & & & \\
C4:0 - & - & - & - & 9.2 & - & - & - \\
C10:0 & & & & & & & \\
C12:0 & 0.5 & 0.7 & 0.4 & 2.9 & - & - & - \\
C14:0 & 1.7 & 1.5 & 2.1 & 10.0 & - & 0.1 & - \\
C16:0 & 48.7 & 41.6 & 68.3 & 29.0 & 10.0 & 6.3 & 4.9 \\
C18:0 & 3.9 & 3.8 & 4.0 & 10.7 & 4.1 & 7.3 & 2.5 \\
C18:1 & 37.1 & 42.0 & 20.6 & 25.6 & 25.2 & 24.3 & 63.6 \\
C18:2 & 8.1 & 10.4 & 4.6 & 2.9 & 53.4 & 65.1 & 21.2 \\
C18:3 & - & - & - & - & 7.3 & - & 7.9 \\
\hline
\end{tabular}


Table 2. TAG profiles of palm fractions in comparison with some common fats and oils ${ }^{22,25-28}$

\begin{tabular}{|c|c|c|c|c|c|c|c|}
\hline TAG species & Palm oil & $\begin{array}{l}\text { Palm } \\
\text { olein }\end{array}$ & $\begin{array}{c}\text { Palm } \\
\text { stearin }\end{array}$ & Milk fat & Soybean & Sunflower & Canola \\
\hline BMP & - & - & - & 3.19 & - & - & - \\
\hline $\mathrm{BPO}$ & - & - & - & 4.40 & - & - & - \\
\hline BPP & - & - & - & 5.39 & - & - & - \\
\hline $\mathrm{CaPO}$ & - & - & - & 2.62 & - & - & - \\
\hline $\mathrm{CaPP}$ & - & - & - & 2.93 & - & - & - \\
\hline CyPO/LLLn & - & - & - & 2.27 & 6.0 & - & 1.0 \\
\hline CPO/LLL & - & - & - & 2.38 & 17.3 & 27.2 & 1.0 \\
\hline CPP/LnLO & - & - & - & 2.68 & 5.1 & - & 7.1 \\
\hline LLO/MMO & 0.4 & 0.4 & - & 3.13 & 17.2 & 29.5 & 7.8 \\
\hline $\begin{array}{l}\text { LLP/MMP/ } \\
\mathrm{LnOO}\end{array}$ & 1.2 & 2.5 & 0.2 & 3.21 & 12.1 & 9.6 & 12.3 \\
\hline LOO/MOO & 1.5 & 1.6 & 0.6 & 3.08 & 8.4 & 11.0 & 22.1 \\
\hline LOP & 8.9 & 11.2 & 5.1 & - & 8.3 & 10.6 & 4.2 \\
\hline PLP & 9.2 & 9.9 & 8.1 & 1.44 & 1.5 & 3.6 & - \\
\hline MOP & - & - & - & 5.23 & - & - & - \\
\hline OOO/PPM & 3.9 & 2.7 & 2.2 & 3.84 & 2.9 & 3.0 & 28.7 \\
\hline POO & 23.3 & 25.3 & 15.3 & 4.14 & 2.2 & 3.5 & 5.7 \\
\hline POP & 30.2 & 34.4 & 35.9 & 5.83 & 0.3 & 0.5 & - \\
\hline PPP & 6.7 & 0.5 & 17.9 & 3.06 & 0.1 & 0.8 & - \\
\hline $\mathrm{SOO}$ & 2.9 & 2.4 & 1.4 & 1.24 & 0.2 & 1.1 & 2.5 \\
\hline POS & 6.7 & 5.6 & 7.1 & 3.45 & 0.4 & 0.4 & - \\
\hline PPS & 1.1 & 0.2 & 3.3 & 2.32 & 0.2 & 0.4 & - \\
\hline
\end{tabular}

B: butyric acid (C4:0), Ca: caproic acid (C6:0), Cy: caprylic acid (C8:0), C: capric acid (C10:0), M: myristic acid (C14:0), P: palmitic acid (C16:0), S: stearic acid (C18:0), O: oleic acid (C18:1), L: linoleic acid (C18:2), Ln: linolenic acid (C18:3) 
Table 3. Thermal properties of some major TAGs in palm oil ${ }^{4,15,18,36-38}$

\begin{tabular}{lcccc}
\hline TAG & Crystallization temperature $\left({ }^{\circ} \mathrm{C}\right)$ & \multicolumn{3}{c}{ Melting temperature $\left({ }^{\circ} \mathrm{C}\right)$} \\
\cline { 3 - 5 } & & $\alpha$ & $\beta$ & $\beta$ \\
\hline PPP & 38.28 & 44.7 & 56.6 & 66.4 \\
POP/PPO & 7.84 & $15.2-18.5$ & $25.3-33.5$ & $35.1-36.7$ \\
POO/OPO & -22.22 & -4 & 12.12 & $18.5-22$ \\
POS/SPO & 8.95 & $17.9-19.6$ & $28.9-33.0$ & $37.1-40.2$ \\
PPL & NA & NA & $21.1-26.5$ & 36.0 \\
\hline
\end{tabular}

NA: not available 
Table 4. Some studies of granular crystals in palm oil based shortenings and margarines

\begin{tabular}{|c|c|c|c|c|c|}
\hline $\begin{array}{l}\text { Fat blends } \\
\text { composition }\end{array}$ & Type* & $\begin{array}{l}\text { Sample } \\
\text { preparation }\end{array}$ & Hypothesis & $\begin{array}{l}\text { Granular crystals } \\
\text { detection }\end{array}$ & Reference \\
\hline $\begin{array}{l}\text { Palm oil, } \\
\text { rapeseed oil }\end{array}$ & $S$ & $\begin{array}{l}\text { Static } \\
\text { crystallization } \\
\text { from } 60^{\circ} \mathrm{C} \text { to } \\
30^{\circ} \mathrm{C} \\
\mathrm{T}_{\text {storage }}: 5^{\circ} \mathrm{C}\end{array}$ & $\begin{array}{l}\text { Polymorphic } \\
\text { transition } \beta \rightarrow \beta \\
\text { crystals of POP }\end{array}$ & PLM, XRD, DSC & 17 \\
\hline $\begin{array}{l}\text { Palm oil, } \\
\text { soybean oil, } \\
\text { milk fat }\end{array}$ & $M$ & $\begin{array}{l}\text { Shear } \\
\text { crystallization } \\
\text { at } 300 \text { rpm } \\
\text { using heat } \\
\text { exchanger } \\
\mathrm{T}_{\text {storage: }} 5^{\circ} \mathrm{C}\end{array}$ & $\begin{array}{l}\text { Agglomeration of } \\
\beta^{\prime} \text { crystals (POP) in } \\
\text { the presence of } \\
\text { POO (liquid fat) }\end{array}$ & PLM, XRD, DSC & 18 \\
\hline $\begin{array}{l}\text { Palm oil, } \\
\text { soybean oil, } \\
\text { hyrogenated } \\
\text { soybean oil, }\end{array}$ & $M$ & $\begin{array}{l}\text { Shear } \\
\text { crystallization } \\
\text { at } 3000 \mathrm{rpm} \\
\text { using } \\
\text { homogenizer } \\
\text { mixer } \\
\mathrm{T}_{\text {storage: }} 5^{\circ} \mathrm{C}\end{array}$ & $\begin{array}{l}\text { Precipitation of } \beta \text { ' } \\
\text { and } \beta \text { crystals (PPP } \\
\text { and POP) }\end{array}$ & PLM, XRD & 15,54 \\
\hline $\begin{array}{l}\text { Palm oil, beef } \\
\text { tallow fat }\end{array}$ & $S$ & $\begin{array}{l}\text { Static } \\
\text { crystallization } \\
\text { using a freezer } \\
\left(-20^{\circ} \mathrm{C}\right)\end{array}$ & $\begin{array}{l}\text { Migration and } \\
\text { aggregation of } \beta \\
\text { crystals }\end{array}$ & PLM, XRD & $14,52,55$ \\
\hline $\begin{array}{l}\text { Palm oil, palm } \\
\text { stearin }\end{array}$ & $M$ & $\begin{array}{l}\text { Shear } \\
\text { crystallization } \\
\text { at } 300 \quad \text { rpm } \\
\text { using ice } \\
\text { cream maker } \\
\mathrm{T}_{\text {storage: }} 28^{\circ} \mathrm{C}\end{array}$ & $\begin{array}{l}\text { Agglomeration of } \\
\text { POP }\end{array}$ & PLM & 53,56 \\
\hline $\begin{array}{l}\text { Palm oil, } \\
\text { soybean oil }\end{array}$ & $M$ & $\begin{array}{l}\text { Shear } \\
\text { crystallization } \\
\text { at } 130 \text { rpm } \\
\text { using heat } \\
\text { exchanger } \\
T_{\text {storage }}: 5^{\circ} \mathrm{C}\end{array}$ & $\begin{array}{l}\text { Polymorphic } \\
\text { transition } \beta \rightarrow \beta \\
\text { crystals of high } \\
\text { melting TAG }\end{array}$ & PLM, XRD & 57 \\
\hline
\end{tabular}

*S: shortening; M: margarine 

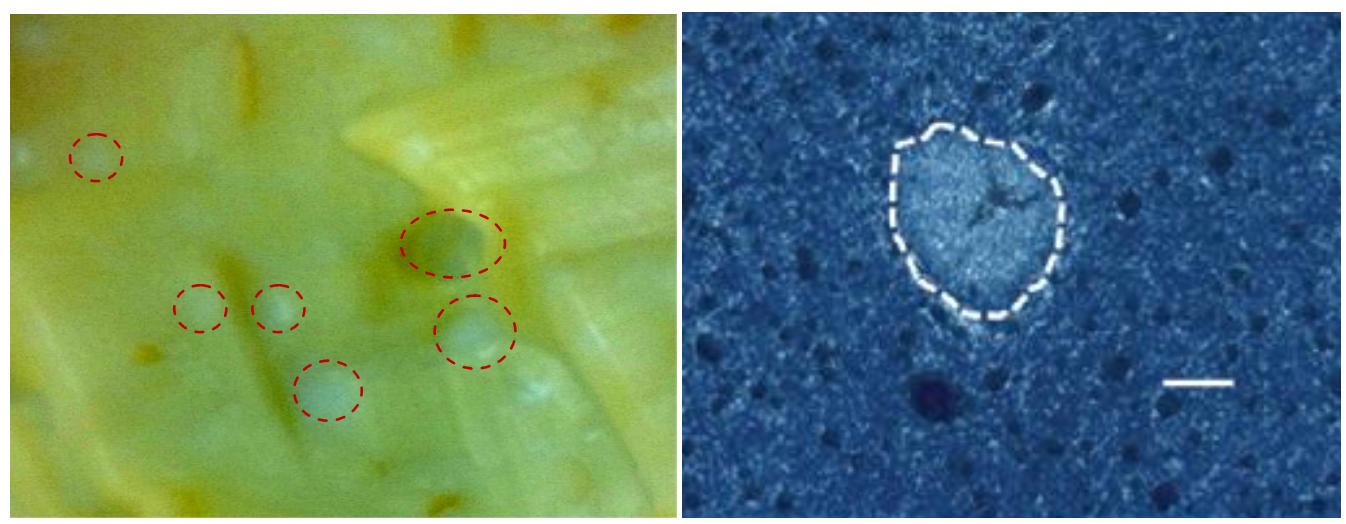

Figure 1. Granular crystals (dotted line circle) in margarine observed by naked eye (industrial products) and by polarized light microscope (reproduced from ${ }^{16}$ with permission from Wiley).
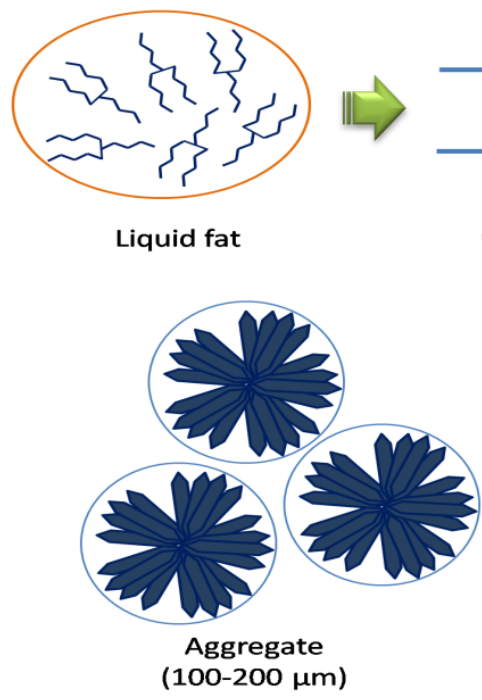

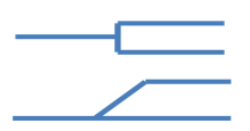

Conformation
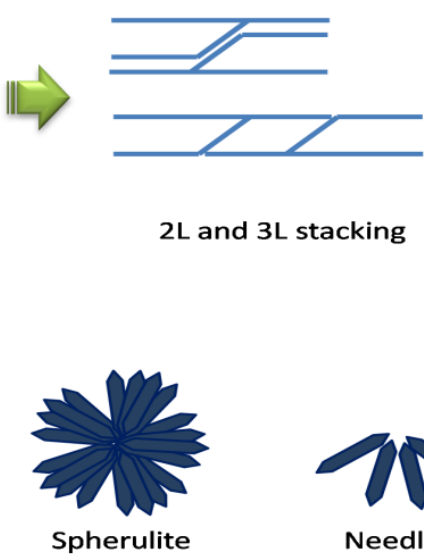
(10-20 $\mathrm{mm}$ )

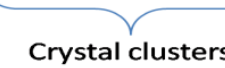

Crystal clusters

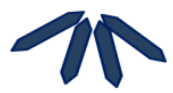

Needle

(1-5 $\mu \mathrm{m}$ )

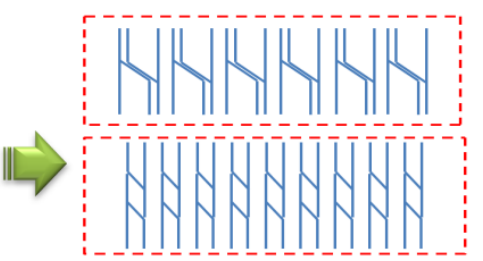

Lamella
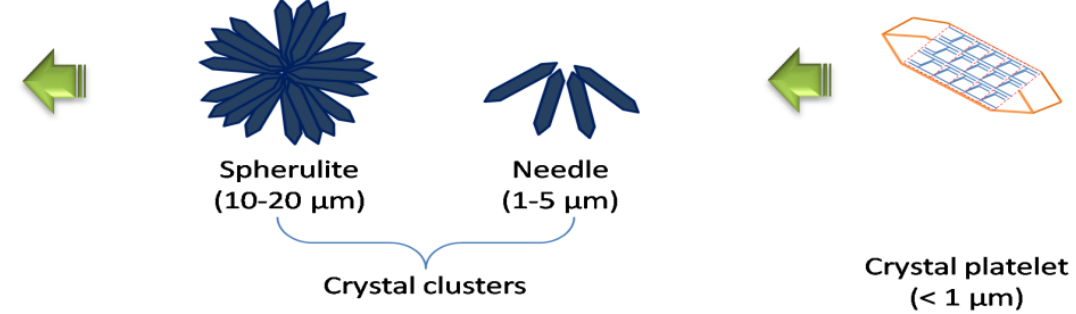

Figure 2. Crystal growth in fat crystallization. Adapted from ${ }^{40,42,44}$ with permission from the Royal Society of Chemistry, Wiley and ACS, respectively. 


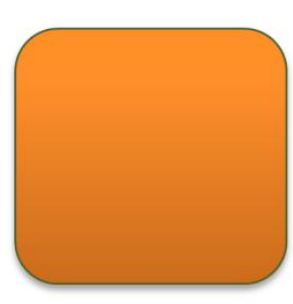

$\boldsymbol{A}$

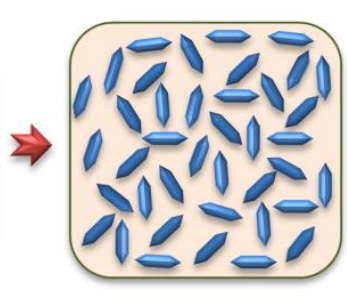

B

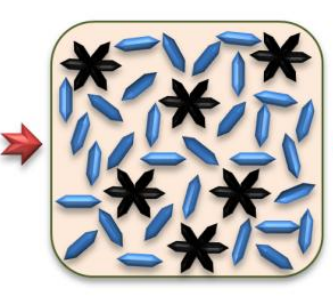

C

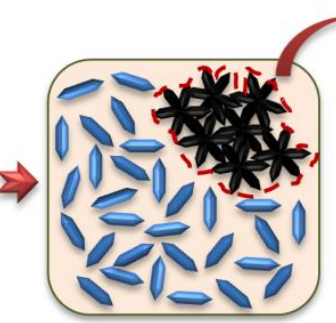

D

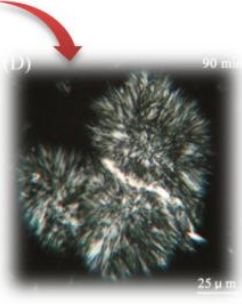

$\boldsymbol{E}$

Figure 3. The formation of granular crystals in palm based shortenings (according to ${ }^{2,14,17,52,53}$ ). $A$ : molten fat; $B$ : shortening (a matrix of needle-like fat crystals under $\beta$ ' form entrapping liquid oils); $C:$ the $\beta^{\prime} \rightarrow \beta$ polymorphic transition in longterm storage palm based shortening accompanies with the formation of spherulite-like crystals ( $\beta$ form); $D$ : the aggregation of spherulite-like crystals, $E$ : granular crystals in palm based shortening observed by polarized light microscope (reproduced from ${ }^{52}$ with permission from ACS). 

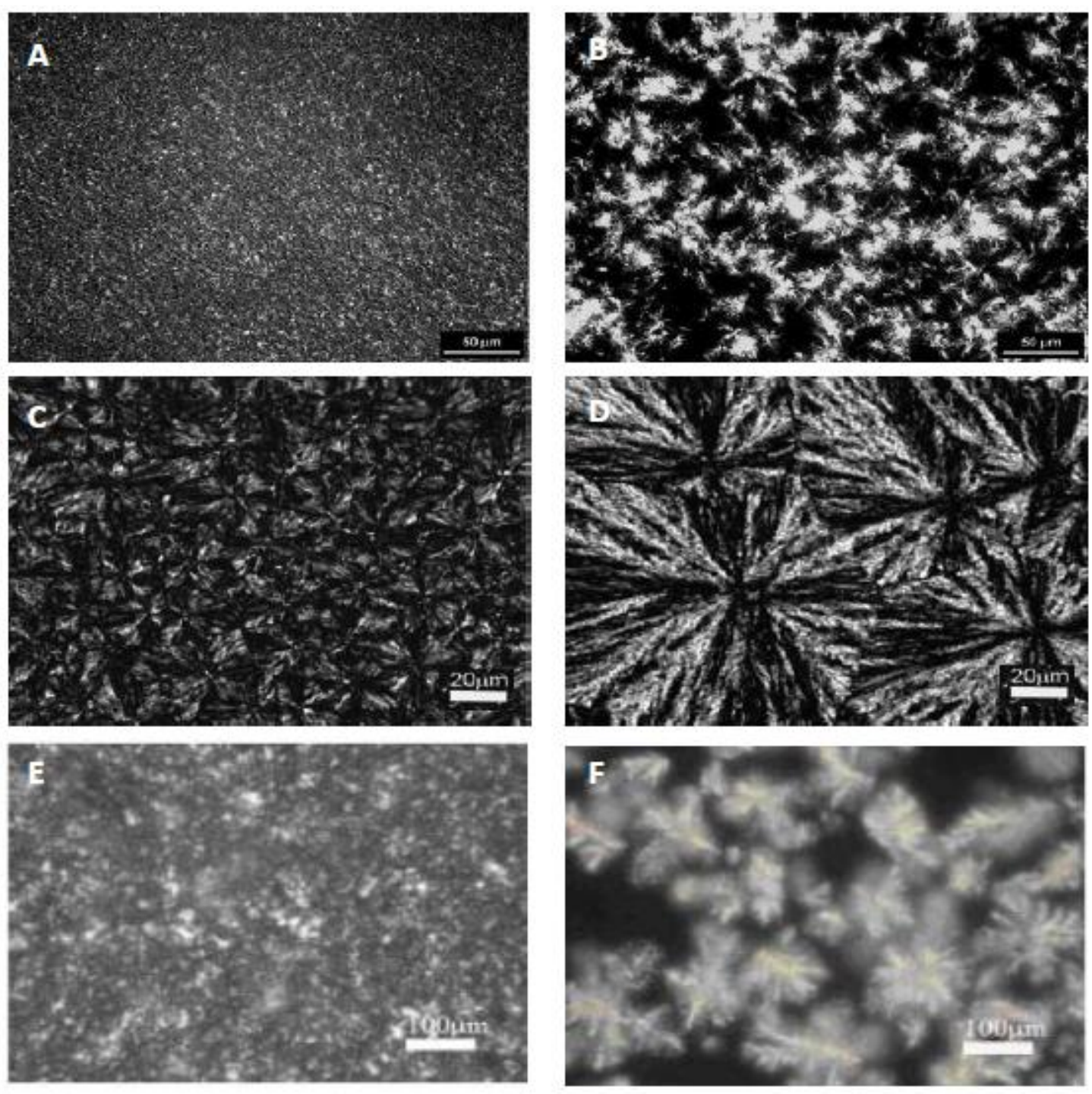

Figure 4. Effect of cooling rate on the size of fat crystals ( $A-B, C-D$ and $E-F$ : milk fat, hydrogenated canola oil and palm fat crystallize under rapid cooling and slow cooling, respectively). Reproduced from ${ }^{76,72,73}$ with permission from Elsevier, Wiley and MDPI (available at https://www.mdpi.com/1420-3049/18/1/1036 under a Creative Commons CC BY

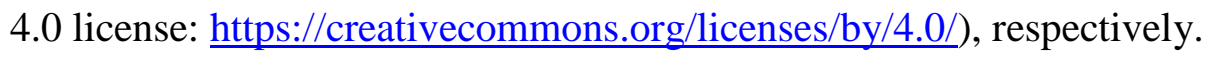

